\title{
Erratum to: Bivalirudin Versus Heparin Plus Glycoprotein IIb/ IIIa Inhibitors in Patients with Diabetes Mellitus Undergoing Percutaneous Coronary Intervention: A Meta-Analysis of Randomized Controlled Trials
}

Uzoma N. Ibebuogu ${ }^{1}$ - Oluwaseyi Bolorunduro ${ }^{1} \cdot$ Smith Giri $^{1}$ - Sam Dagogo-Jack ${ }^{2}$ •

Blake G. Smith ${ }^{1} \cdot$ Saibal Kar $^{3} \cdot$ Guy L. Reed ${ }^{1}$

Published online: 1 April 2015

(C) Springer International Publishing Switzerland 2015

Erratum to: Am J Cardiovasc Drugs

DOI 10.1007/s40256-015-0113-8

Key points, second sentence which previously read:

The benefits of bivalirudin were seen mainly in DM patients undergoing effective PCI.

Should read:

The benefits of bivalirudin were seen mainly in DM patients undergoing elective PCI.

The online version of the original article can be found under doi:10.1007/s40256-015-0113-8.

Uzoma N. Ibebuogu

uibebuog@uthsc.edu; Ibebuogu@gmail.com

1 Division of Cardiovascular Diseases, University of Tennessee Health Sciences Center, 365 Court Avenue, Suite D334, Memphis, TN 38163, USA

2 Division of Endocrinology, University of Tennessee Health Sciences Center, Memphis, TN, USA

3 Heart Institute, Cedars-Sinai Heart Institute, Los Angeles, CA, USA 